\title{
A novel operation cost optimization system for mix-burning coal slime circulating fluidized bed boiler unit
}

Zhang, Wei; Liu, Jizhen; Gao, Ming-ming; Huusom, Jakob K.

Published in:

Applied Thermal Engineering

Link to article, DOI:

10.1016/j.applthermaleng.2018.11.087

Publication date:

2019

Document Version

Peer reviewed version

Link back to DTU Orbit

Citation (APA):

Zhang, W., Liu, J., Gao, M., \& Huusom, J. K. (2019). A novel operation cost optimization system for mix-burning coal slime circulating fluidized bed boiler unit. Applied Thermal Engineering, 148, 620-631.

https://doi.org/10.1016/j.applthermaleng.2018.11.087

\section{General rights}

Copyright and moral rights for the publications made accessible in the public portal are retained by the authors and/or other copyright owners and it is a condition of accessing publications that users recognise and abide by the legal requirements associated with these rights.

- Users may download and print one copy of any publication from the public portal for the purpose of private study or research.

- You may not further distribute the material or use it for any profit-making activity or commercial gain

- You may freely distribute the URL identifying the publication in the public portal 


\section{Accepted Manuscript}

A Novel Operation Cost Optimization System for Mix-burning Coal Slime Circulating Fluidized Bed Boiler Unit

Wei Zhang, Jizhen Liu, Ming-ming Gao, Jakob K. Huusom

PII:

S1359-4311(18)33633-0

DOI: https://doi.org/10.1016/j.applthermaleng.2018.11.087

Reference: ATE 12968

To appear in:

Applied Thermal Engineering

\section{APPLIED}

THERMAL

ENGINEERING

$\begin{array}{ll}\text { Received Date: } & \text { 14 June } 2018 \\ \text { Revised Date: } & 7 \text { October } 2018\end{array}$

Accepted Date: $\quad 21$ November 2018

Please cite this article as: W. Zhang, J. Liu, M-m. Gao, J.K. Huusom, A Novel Operation Cost Optimization System for Mix-burning Coal Slime Circulating Fluidized Bed Boiler Unit, Applied Thermal Engineering (2018), doi: https://doi.org/10.1016/j.applthermaleng.2018.11.087

This is a PDF file of an unedited manuscript that has been accepted for publication. As a service to our customers we are providing this early version of the manuscript. The manuscript will undergo copyediting, typesetting, and review of the resulting proof before it is published in its final form. Please note that during the production process errors may be discovered which could affect the content, and all legal disclaimers that apply to the journal pertain. 


\title{
A Novel Operation Cost Optimization System for Mix-burning Coal
}

\section{Slime Circulating Fluidized Bed Boiler Unit}

\author{
Wei Zhang ${ }^{* 1,2}$, Jizhen Liu ${ }^{1}$, Ming-ming Gao ${ }^{1}$, Jakob K. Huusom ${ }^{2}$
}

1. State Key Lab of Alternate Electric Power System With Renewable Energy Sources, North China Electric Power University, Changping District, Beijing 102206, China;

2. Process and Systems Engineering Center, Department of Chemical and Biochemical Engineering, Technical University of Denmark, Building 229, 2800 Kgs. Lyngby, Denmark

ABSTRACT: At present, mix-burning of coal slime in a circulating fluidized bed boiler is an effective method to cleanly utilize low-price coal slime. This study proposed a data-based operation cost optimization system for mix-burning coal slime CFB boiler unit that instructs operators to more scientifically adjust the operation parameters. Based on actual operating data from a 300MW CFB unit, least squares support vector machine was used to build the steady-state operation cost model, and partial mutual information variable selection method was applied to choose the input variables and lower the model complexity. Based on the pre-built operation cost model, the genetic algorithm was used to establish an offline expert knowledge database within the safety threshold range. The utility cost was introduced into association rule measurement standards to improve the traditional fuzzy association rules mining. The improved fuzzy association rule mining was used to extract the associations between the unit load and the optimal operation parameters from the off-line expert knowledge database after receiving the load instruction, so as to achieve fast instruct on online operation optimization. Results showed that the proposed economic optimization system performances were better than traditional methods and can improve operation of the unit being studied.

KEY WORDS: Circulating fluidized bed; partial mutual information; least squares support vector machine; genetic algorithm; improved fuzzy association rule mining

\section{Introduction}

In January, 2018, the four major Chinese thermal power groups jointly published an urgent report on the current situation of coal supply for power generation, the report implies that the supply of coal has gradually become tenser in China, and the price of CCI5500 power coal rose 34\% in 2017 [1]. In the Annual Energy Outlook 2017 (AEO), the U.S. Energy Information Administration (EIA) projects

\footnotetext{
* Corresponding author. Tel.:+8618810278985;

E-mail address: weizhang@ncepu.edu.cn (Wei Zhang).
} 
that coal prices will generally increase through the year 2050 [2].Besides, Coal India has raised prices of thermal coal by an average 9\% [3]. Thus developing alternative fuel technology in accordance with local conditions for thermal power plants is highly necessary. The coal slime as by-products of coal washing only cost one-sixth of the price of coal, thus the efficient utilization of the coal slime is an urgent problem for thermal power plants all over the world.

Coal slime is characterized by high water content, high viscosity and low heating value [4], which imposing restrictions on its large-scale application. Operation parameters of circulating fluidized bed (CFB) unit such as the bed temperature, the exhaust temperature, and the boiler efficiency will fluctuate after the coal slime is sent into the furnace. On the one hand, the cheap coal slime can save the fuel cost. On the other hand, with too high share of the coal slime in the fuel mixture, mix-burning coal slime in CFB boiler affects the stable operation, pollutant emission, and power consumption of CFB boiler units [5]. Besides, the complexity in the actual continuous operation process is not easy to be presented in control and simulation in researches. Therefore, it is difficult to form an effective, sustainable and stable optimization system only relying on theoretical knowledge. Therefore it is of great significance to use the actual data and construct an operation optimization system for a CFB boiler unit under the premise of stable operation.

The recording and accessing of large amounts of real operational data in databases is allowed by the wide available application of a distributed control system (DCS), which provides a convenient platform for model validation and optimization guidance of the CFB unit operation. Many researches used operational data to study large-scale CFB boiler operation and provided the accessible data. Lv et al. [5] presented a dynamic model for predicting the bed temperature of a 300 MWCFB boiler based on the least squares support vector machine (LSSVM) method with real operational data. This accurate model to describe the dynamic characteristics of bed temperature was beneficial in reducing temperature fluctuations. Blaszczuk et al. [6] proposed a population balance model enabling a stationary-regime modeling of the mass flow of granular matter inside a 966MW supercritical CFB unit. From this model, some calculations of operational parameters for the CFB reactor were presented that show consistency with the operational data. The simulation model is a good tool to monitor the particle-size distribution during operation conditions of CFB combustion systems in a large-scale. Besides, for the same supercritical circulating fluidized bed unit, Blaszczuk et al. [7] carried out experimental tests on a full-scale DeNOx system to determine the impact of operating conditions on the 
deNOx system efficiency. Parameters including ammonia mass flow, a spray pressure of air, O2 concentration and flue gas temperature were studied, and the effects of these operation parameters on NOx emission can supply operation guidance for reduce NOx emission. Jiang et al. [8] added the coal consumption into the objective function of dynamic matrix controller. According to the actual requirements, the operation point of the boiler was permitted to change within a zone, whose control logic in dynamic matrix controller provided the freedom to reduce the coal consumption. The proposed method was verified to be remarkable coal-saving by the data of a $150 \mathrm{t} / \mathrm{h}$ boiler of a CFB power plant.

In existing research related to optimization of CFB boiler unit, there are two types of studies. The first type concerns on boiler operation optimization, and the majority focuses only on the combustion process in furnace, these usually aim to achieve stability optimization. Gao et al. [9] proposed a double-feedforward self-balance feed water instruction based on the steam water balance theory, which overcame the large delay and inertia of the boiler and realizes the accurate feed water control when load changes. Hadavand et al. [10] obtained a state space dynamical model oriented to bed temperature based on subspace method, a robust control algorithm based on linear matrix inequalities (LMI) have been applied to control the bed temperature by input parameters. The second type involves economic optimization but focus on the coal consumption, thermal efficiency, or pollutants treatment, which only concern the economic optimization of the boiler operation or pollutants treatment process rather than plant-level operation. Wang et al. [11] proposed an idea of energy-consumption benchmark state. The energy analytics was introduced to determine the energy-consumption benchmark state, of which the coal rate is considerably less than that of the actual state with the same operation boundaries. Yang et al. [12] proposed a real operation data-based denitration cost optimization system that guided operators in economically adjusting the operation parameters of boilers. The system had excellent performance from aspects of denitration cost, optimization time, and update time. However, the above optimization systems often aim for low coal consumption, high efficiency combustion, and low emissions, which lead to a non-intuitive result of the economic evaluation for the mix-burning coal slime CFB boiler unit. Few researches have studied the whole unit's economic optimization, including fuel cost, gaseous emission technology cost, and plant electricity consumption cost.

The operation cost of mix-burning coal slime CFB unit is dynamically time-depended and of uncertainties especially under the off-designed working conditions and operation boundaries. The fuzzy logic is an ideal nonlinear control method, which has excellent robustness, adaptability and fault 
tolerance. There are many researches on the application of fuzzy logic in CFB boilers. Krzywanski et al. presented the key features of the fuzzy logic approach as a cost-effective technique in simulations in Ref. $[13,14]$. The fuzzy logic model allowed predicting the bed-to-wall heat transfer coefficient in a large-scale $670 \mathrm{t} / \mathrm{h}$ CFB boiler. The local heat transfer coefficients evaluated were in very good agreement with the desired data. Blaszczuk et al. [15] established the interrelation between fuzzy logic and cluster renewal approaches for heat transfer modeling in a circulating fluidized bed (CFB) based on a local furnace data. The effects of parameters such as bed temperature and suspension density on the overall heat transfer coefficient were studied. The goodness of the fit of prediction values was found to be 0.99 for heat flux recovery by the fuzzy logic system, which was proved as a good tool.

The core of the fuzzy logic system is how to quickly obtain the associations, and the method of fuzzy association rule mining (FARM) has attracted much attention, because its unique advantages are simple, fast, and satisfies online application conditions method [12]. Mangalampalli et al. [16] improved fuzzy Apriori algorithms for fast performance on large datasets. Individual item set processing was adopted as opposed to simultaneous item set processing at each k-level in the second phase of algorithms. However, like all traditional FARM methods, minimum support and minimum confidence were used as the criteria of association rules selection, which cannot ensure to get the unique and the most valuable association rule result. Besides, Li et al. [17] used the coal consumption of the pulverized coal-fired boiler unit as the optimization target, and built an operation optimization by three steps including transforming fuzzy sets of historical data, selecting association rules, and fuzzy control. An index "Interest" which was a function of membership was adopted as the criteria of association rules selection, which measures the degree of concern for the rules. However, the requirements for the stability and economy of the unit were not reflected in the association rules selection criteria. According to the above analysis, it is inevitable that deviations exist on the condition of single judgment criteria. Consequently, the "Utility cost" index based on the "Interest" index is introduced into association rule measurement standards. The improved fuzzy association rules mining (IFARM) is used to extract the associations between the load and the optimal condition for unit economy.

The main contribution of this study is to propose a data-based operation cost optimization system for CFB boiler unit that supplies fast instructions on the target values of operation parameters after receiving the load instruction. The optimization function was achieved by actual operation data of a 
300MW mix-burning coal slime CFB boiler unit, which was quite valuable but rarely reported.

PMI-LSSVM method was used to build an operation cost model described a relationship between the selected input variables and operation cost. The optimal operation state of the unit was extracted by IFARM method based on the off-line expert knowledge database (EKD) under safe threshold. Both the prediction model and the optimization strategy were compared with other methods. The sampling data and research results can provide reference for other researches on CFB boiler units.

The remainder of the paper is organized as follows: Section 2 introduces the principle and construction of the operation cost optimization system. Section 3 employs the application of the system in an actual mix-burning coal slime CFB boiler unit power plant. Section 4 discusses the conclusions.

\section{Principle and construction of operation cost optimization system}

In this section, all algorithms and overall design structures of the operation cost optimization system are introduced. There are four main algorithms and they are partial mutual information (PMI) algorithm, LSSVM algorithm, genetic algorithm (GA), and IFARM algorithm respectively. According to the real-time characteristics of signals, the optimization system is divided into two parts: the off-line part and the on-line part. From the angle of the function structure, the optimization system falls into three categories: the operation base, the model algorithm base, the expert knowledge base. Above structure divisions are illustrated in Fig. 1.

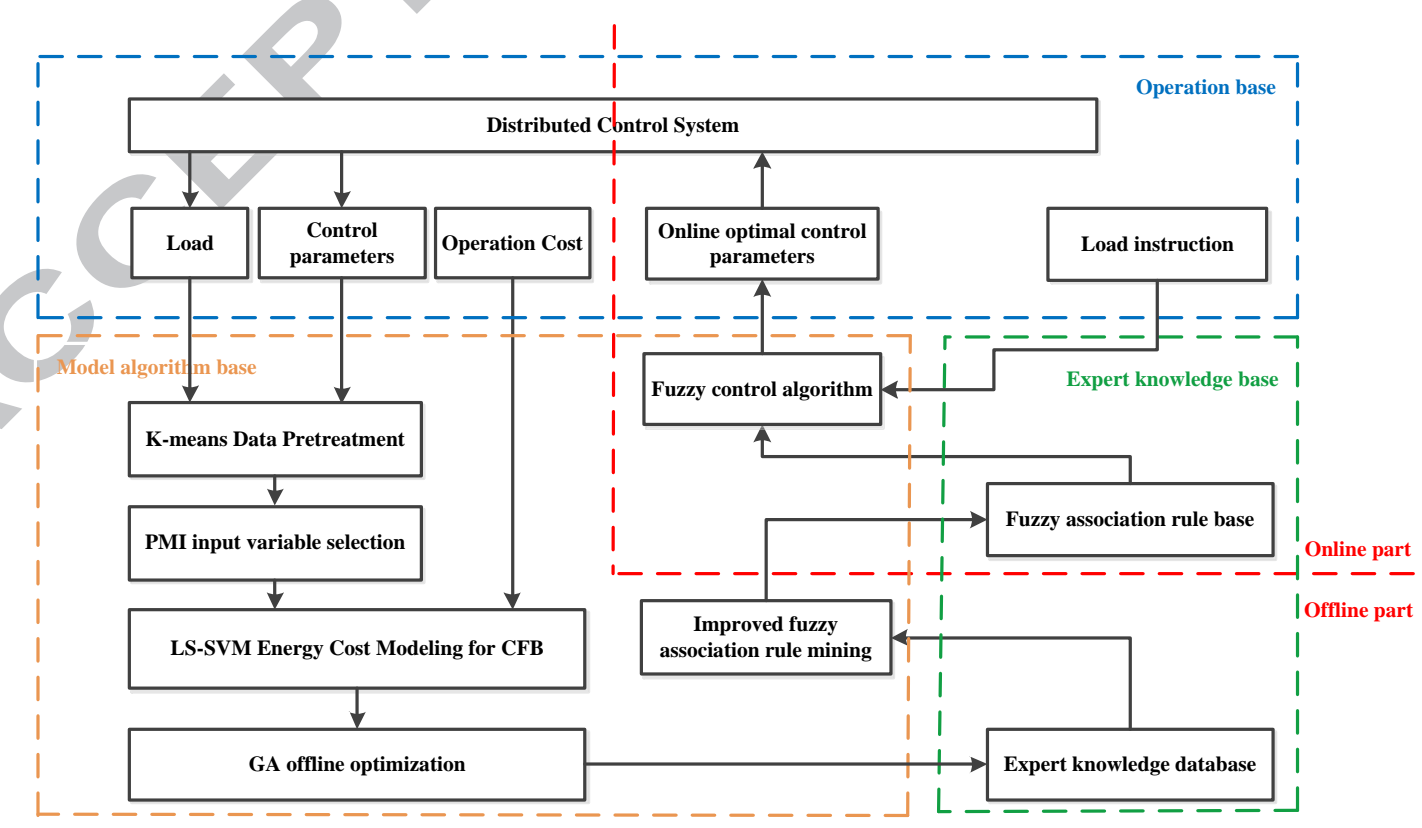

Fig. 1 Structure of operation cost optimization system of unit

\subsection{Variable selection method based on PMI}


The information entropy theory was proposed by Shannon in 1948[18], as a probability statistical method, it used the entropy as a measure of information. The information entropy can be calculated as:

$$
H(X)=-\sum_{i=1}^{n} p_{i} \log p_{i}
$$

where $H(\boldsymbol{X})$ represents the information entropy of $\boldsymbol{X}, 0 \leq p_{i} \leq 1$ is the probability distribution under different values of $\boldsymbol{X}, n$ is the number of data. If the joint probability distribution of the random vector $(\boldsymbol{X}, \boldsymbol{Y})$ is defined as $p_{i j}(i=1,2, \ldots, n ; j=1,2, \ldots, n)$, the two-dimensional joint entropy of $(\boldsymbol{X}, \boldsymbol{Y})$ can be defined as:

$$
H(X, Y)=-\sum_{i, j=1}^{n} p_{i j} \log p_{i j}
$$

If the marginal distributions of $\boldsymbol{X}$ and $\boldsymbol{Y}$ are assumed to be $p_{i}$ and $p_{j}$ respectively, when $\boldsymbol{Y}$ is known, the conditional entropy of $\boldsymbol{X}$ can be defined as

$$
H(X / Y)=-\sum_{i, j=1}^{n} p_{i j} \log \frac{p_{i j}}{p_{\bullet j}}
$$

$H(\boldsymbol{X} / \boldsymbol{Y}) \leq H(\boldsymbol{X})$ shows that $\boldsymbol{Y}$ contains some information of $\boldsymbol{X}$, the information shared by $\boldsymbol{X}$ and $\boldsymbol{Y}$ is the partial mutual information $\boldsymbol{I}(\boldsymbol{X}, \boldsymbol{Y})$.

$$
I(X, Y)=H(X)-H(X / Y)
$$

In general, probability distributions of $\boldsymbol{X}$ and $\boldsymbol{Y}$ are unknown, and therefore the kernel density estimation is adopted as substitution [19]. The partial mutual information can be calculated as:

$$
\begin{gathered}
I(X, Y)=\frac{1}{n} \sum_{i=1}^{n} \log \left[\frac{f\left(x_{i}, y_{i}\right)}{f\left(x_{i}\right) f\left(y_{i}\right)}\right] \\
f(x)=\frac{1}{n(\sqrt{2 \pi} h)^{d} \sqrt{\left|\sum\right|}} \sum_{i=1}^{n} \exp \left(\frac{-\left\|x-x_{i}\right\|}{2 h^{2}}\right) \\
h=\left(\frac{1}{d+2}\right)^{1 /(d+4)} n^{-1 /(d+4)}
\end{gathered}
$$

where $n$ is the number of observation samples, $h$ is the kernel bandwidth; $d$ is the dimension of $\boldsymbol{X}$. When $\boldsymbol{X}$ is one-dimensional, $\Sigma$ is the variance of $\boldsymbol{X}$; when $\boldsymbol{X}$ is multidimensional, $\Sigma$ is the covariance matrix; $|\Sigma|$ is the determinant of the matrix.

The relationship between entropy, joint entropy, condition entropy and mutual information is 
shown in Fig. 2.

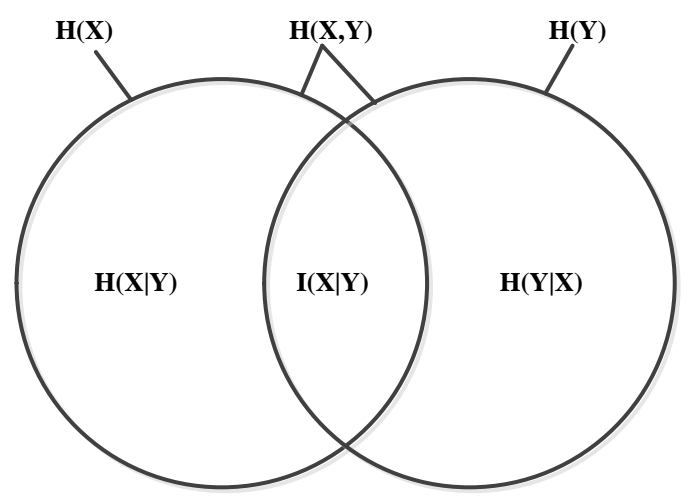

Fig. 2 Relationship between entropy, joint entropy, condition entropy and mutual information

With regard to multi-input systems, for example, $\boldsymbol{X}$ and $\boldsymbol{Y}$ are input variables, and $\boldsymbol{Z}$ is the output variable, if there is a connection between $X$ and $\boldsymbol{Y}$, the calculated value of $I(Z, Y)$ will be greater than the actual value. Thus, the information of $\boldsymbol{X}$ contained in $\boldsymbol{Y}$ and $\boldsymbol{Z}$ should be eliminated using the conditional expectation, and the correlation degree among variables should be measured by PMI. $\boldsymbol{Y}$ and $\boldsymbol{Z}$ after being eliminated of $\boldsymbol{X}$, are respectively expressed as $\boldsymbol{u}$ and $\boldsymbol{v}$, the relevant formulas are as follows:

$$
\begin{gathered}
m_{Y}(x)=E[y \mid X=x]=\left[\sum_{i=1}^{n} y_{i} f(x)\right] /\left[\sum_{i=1}^{n} f(x)\right] \\
u=Y-m_{Y}(X) \\
v=Z-m_{Z}(X)
\end{gathered}
$$

The partial mutual information between $\boldsymbol{Y}$ and $\boldsymbol{Z}$ is expressed as:

$$
I(Y, Z)=I(u, v)
$$

Assuming that the set of input variables is $\boldsymbol{C}$, the output variable is $\boldsymbol{Z}$, the optimal set of input variables is $\boldsymbol{S}$, and $\boldsymbol{C s}$ is the candidate variable corresponding to the maximum PMI value, the procedure of variable selection method based on PMI is as follows:

1) Initialize $S$ and set it to an empty set;

2) When $C \neq \varphi$;

3) Calculate $\boldsymbol{u}=\boldsymbol{Z}-m_{Y}(\boldsymbol{S})$;

4) For each $\boldsymbol{C}_{j} \in \boldsymbol{C}$, calculate $\boldsymbol{v}=\boldsymbol{C}_{j}-m_{c j}(\boldsymbol{S})$;

5) Select the $\boldsymbol{C s}$ which corresponds to the maximum value of $\boldsymbol{I}(\boldsymbol{u}, \boldsymbol{v})$;

6) Calculate the value of Akaike information criterion (AIC), if the AIC decreases, Cs should be 
moved into $S$, return to step 2; if the AIC does not decrease, stop selecting.

The AIC can be calculated as:

$$
\mathrm{AIC}=n \log \left(\frac{1}{n} \sum_{i=1}^{n} u_{i}^{2}\right)+2\left(n_{v}+1\right)^{2}
$$

where $\boldsymbol{u}_{i}$ is the regression residual of $\boldsymbol{Z} ; n$ is the sampling amount; $n_{v}$ is the number of selected variables. With the selection of independent variables, the value of AIC constantly decreases. When the AIC reaches the minimum value, the optimal set of independent variables is completely extracted.

\subsection{LSSVM data-driven model}

The square term is adopted as the optimization index of LSSVM, and inequality constraints are replaced with equation constraints. So the quadratic programming problem is transformed into a system of linear equations to solve, which greatly reduces the computational complexity and improves the speed of solving.

$\left\{\left(x_{i}, f_{i}\right)\right\}_{i=1}^{\mathrm{n}}$ is a given $\mathrm{n}$-dimensional data set, where the input $\boldsymbol{x}_{\boldsymbol{i}}$ is the independent vector including the control parameters of operation state, the output $f_{i}$ is the operation cost of unit, the input sample $x_{i} \in \mathrm{R}^{\mathrm{p}}$, the output sample $f_{i} \in \mathrm{R}$. The LSSVM regression model can be expressed in the following form [4]:

$$
f_{i}=w^{T} \varphi\left(x_{i}\right)+b
$$

where $\boldsymbol{w}$ is the weight vector; $\varphi(\cdot)$ is a nonlinear mapping; $b$ is the bias. LSSVM uses the square error sum as the loss function and the optimization problem is simplified as:

$$
\left\{\begin{array}{c}
\min _{w, b, \xi} J(w, \xi)=\frac{1}{2} w^{T} w+\frac{1}{2} \gamma \sum_{i=1}^{n} \xi^{2} \\
\text { s.t. } f_{i}=w^{T} \varphi\left(x_{i}\right)+b+\xi_{i}, i=1,2, \cdots, \mathrm{n}
\end{array}\right.
$$

where $\xi$ is the error variable vector; $\boldsymbol{\gamma}$ is the penalty coefficient.

The Lagrange multiplier method and KKT conditions are used to solve the optimization problem, and after eliminating related variables, the solutions can be transformed into a linear equation group:

$$
\left[\begin{array}{cc}
0 & \overrightarrow{1}^{T} \\
\overrightarrow{1} & \Omega+1 / \gamma \cdot I
\end{array}\right]\left[\begin{array}{l}
b \\
\alpha
\end{array}\right]=\left[\begin{array}{l}
0 \\
f
\end{array}\right]
$$

where $\overrightarrow{1}=[1, \ldots, 1]_{\mathrm{n}}{ }^{\mathrm{T}} ; \boldsymbol{\Omega}=\left\{\Omega_{\mathrm{ij}} \mid \mathrm{i}, \mathrm{j}=1, \ldots, \mathrm{n}\right\}$, and $\Omega_{\mathrm{ij}}=\varphi\left(x_{\mathrm{i}}\right)^{\mathrm{T}} \varphi\left(x_{\mathrm{j}}\right)=K\left(x_{\mathrm{i}}, x_{\mathrm{j}}\right)$ is the kernel function; I is a $\mathrm{n} \times \mathrm{n}$ element matrix; $\alpha=\left[\alpha_{1}, \ldots, \alpha_{\mathrm{n}}\right]^{\mathrm{T}}$ is the Lagrange multiplier vector; $f=\left[f_{1}, \ldots, f_{\mathrm{n}}\right]^{\mathrm{T}}$. 
In this study, the widely-used radial basis function (RBF) is adopted as the kernel function of LSSVM, which can be expressed as:

$$
K\left(x, x_{i}\right)=\exp \left(-\left\|x-x_{i}\right\|^{2} / \sigma^{2}\right)
$$

where $\sigma$ is the kernel parameter.

After solving equations and substitution, the LSSVM is finally obtained as:

$$
f(x)=\sum_{i=1}^{n} \alpha_{i} K\left(x, x_{i}\right)+b
$$

The data-driven LSSVM model in this study adopted the sliding window technology as regular update strategy to avoid the model failure caused by the change of unit performance with time, and the strategy can ensure the accuracy of the model and the optimization effect of GA on operation states in the EKD.

\subsection{GA offline optimization}

In the control parameters of operation state, the load is expressed as $Q$ and the other selected input control variables are expressed as $x_{-Q}$. The operation cost prediction model of mix-burning coal slime CFB unit reflects the nonlinear relationship between the operation cost of unit $f$ and the control parameters including $Q$ and $x_{-Q}$.

$$
f=f\left(Q, x_{-Q}\right)
$$

The GA is utilized off-line to optimize the $x_{-Q}$ under the corresponding unit load $Q$ and construct the EKD. The $x_{-Q}$ is real-coded to improve optimization efficiency. In addition, in order to guarantee the stability of operation, for optimal control parameters of operation states, it's necessary to ensure no wide fluctuations under the steady state. Therefore, the search of $x_{-Q}$ needs to be determined by threshold limit and iterative operation, which satisfy safe threshold of historical data.

The EKD is established off-line, thus it requires high accuracy of data. Theoretically, GA can meet the requirements for the data precision and the global optimum of the off-line EKD. Moreover, GA has slow search speed and high computational complexity, but these defects will not affect the performance of the off-line EKD. As a result, GA is a candidate to be the ideal optimization algorithm for establishing the off-line EKD.

\subsection{IFARM for on-line operation cost optimization}

The IFARM algorithm extracted fuzzy association rules between the load and the corresponding optimal control variables in the EKD, and the fuzzy association rules form an association rule base 
which is used in the fuzzy control algorithm. When a unit load instruction is received, fuzzy control algorithm make reasoning and decision according to fuzzy association rules base, and then online optimal control parameters can be used as referenced operation guidance.

The fuzzy association rules are the implication statement of fuzzy item sets associated with the load $Q$ and the control variables $X_{-}$, and there is no intersection between the two fuzzy item sets. The association rule adopts the "If-Then" phrase, which can be described as follows:

If $Q=Q^{m}$,

Then $X_{-Q 1}=X_{-Q 1}{ }^{m}, X_{-Q 2}=X_{-Q 2}{ }^{m}, \ldots, X_{-Q i}=X_{-Q i}{ }^{m}$

where $m$ is the serial number of different operation states in the EKD; $i$ is the serial number of different control variables $X_{-Q}$ under the same operation state.

For the traditional method of fuzzy association rule mining, the association rule $Q \Rightarrow X_{-Q}$ is selected on the basis of the support $s$ and the confidence $c$, whose expressions are respectively shown as:

$$
\begin{gathered}
s\left(Q \Rightarrow X_{-Q}\right)=s\left(Q \cup X_{-Q}\right) \\
=\sum_{j=1}^{m} \mu\left(Q \cup X_{-Q}\right) / m \\
c\left(Q \Rightarrow X_{-Q}\right)=s\left(Q \cup X_{-Q}\right) / s(Q) \\
=\sum_{j=1}^{m_{t}} \mu\left(Q \cup X_{-Q}\right) / \sum_{j=1}^{m_{t}} \mu(Q)
\end{gathered}
$$

where $\mu(Q)$ is the membership function of $Q ; m_{t}$ represents the total number of transactions in the data set; $\boldsymbol{j}$ is the serial number of different transactions in the data set, the two indexes are calculated according to the rules of membership degree operation. The minimum support $\boldsymbol{s}_{\min }$ and the minimum confidence $\boldsymbol{c}_{\text {min }}$ specify the thresholds of support and confidence, and the association rules must meet the $s_{\min }$ and $\boldsymbol{c}_{\min }$ to be established. That is, the following conditions must be satisfied:

$$
s\left(Q \Rightarrow X_{-Q}\right) \geq s_{\min }, \quad c\left(Q \Rightarrow X_{-Q}\right) \geq c_{\min }
$$

1) Introduction of the association rules selection criteria - Utility cost

When using the $\boldsymbol{s}_{\min }$ and $\boldsymbol{c}_{\min }$ to extract association rules in the EKD, the most valuable and representative result cannot be obtained, because too many inference rules can meet the requirements of the $\boldsymbol{s}_{\min }$ and $\boldsymbol{c}_{\min }$, and these association rules usually contradict with each other and mislead the control algorithm's decision making. In that case, if the control algorithm receives a given unit load instruction $Q$, there are different operation states corresponding to redundant rules, which results in the failure of optimization. So the $\boldsymbol{s}_{\min }$ and $\boldsymbol{c}_{\min }$ are used to preliminarily delete the redundant fuzzy 
association rules.

In this paper, the fuzzy association rules selection criteria utility cost is based on the concept of Interest. The Interest index $I$ is a measurement of research interest to the rules [17], and the utility cost is a comprehensive consideration of the interest measure and the economy. The greater the value of utility cost is, the better the economy of the unit is. And utility cost can be expressed as $E$, and its computational formulas are as follows:

$$
\begin{gathered}
I\left(Q \Rightarrow X_{-Q}\right)=\frac{1-s\left(X_{-Q}\right)}{[1-s(Q)] \times\left[1-s\left(Q \cup X_{-Q}\right)\right]} \\
F_{e}\left(Q \Rightarrow X_{-Q}\right)=F_{e}\left(Q \cup X_{-Q}\right) \\
=\sum_{i=1}^{n} f_{e}\left(Q \cup X_{-Q}\right) /\left|n_{r}\right| \\
E\left(Q \Rightarrow X_{-Q}\right)=\frac{I\left(Q \Rightarrow X_{-Q}\right)}{F_{e}\left(Q \Rightarrow X_{-Q}\right)}
\end{gathered}
$$

where $\boldsymbol{F}_{e}$ is the economic index of the fuzzy item sets, $f_{e}$ is the normalized operation cost of unit in the EKD, which is stored in the EKD as a numeric value. $n_{r}$ is the number of the rules.

2) IFARM reasoning and decision making algorithm

In order to reduce the complexity of the algorithm, the association rules between each $X_{-Q}$ and $Q$ are extracted respectively. Then, the redundant fuzzy association rules are deleted on the basis of the minimum support, the minimum confidence and the utility cost. The steps of the IFARM reasoning and decision making algorithm are as follows:

Step1: Normalize the $Q$ and $X_{-Q}$ in the EKD;

Step2: Fuzzify the $Q$ and $X_{-Q}$, then obtain the corresponding fuzzy value;

Step3: By means of fuzzy level discretization and membership degrees calculation, fuzzy value can be transformed into fuzzy vectors in the EKD which make up with the initial fuzzy association rule base Rule1;

Step4: Calculate the minimum support and the minimum confidence of each fuzzy association rule in Rule1 according to Eq. (19) and Eq. (20), then delete the fuzzy association rules whose support and confidence are below the $\boldsymbol{s}_{\min }$ and $\boldsymbol{c}_{\min }$, after arrangement and counting, the fuzzy association rule base Rule2 is obtained;

Step5: Calculate the utility cost of different fuzzy rules according to Eq.(24) and select fuzzy 
association rules according to the principle of the largest utility cost, then the final fuzzy association rule base Rule3 is obtained;

Step6: When receiving a unit load instruction, the fuzzy controller algorithm utilizes Rule3 for reasoning and decision making, after that the fuzzy parameters of the optimal operation state can be obtained;

Step7: Defuzzify the fuzzy parameters to obtain the online parameters of the optimal operation state as the outputs.

\section{Application on operation cost optimization}

This section introduces an application on the case power plant, there are five parts and they are the study object introduction, the preparation for modeling includes input selection and output sample calculation, the modeling of operation cost, the expert knowledge database establishment, and the operation cost optimization respectively.

\subsection{Case power plant description}

This study mainly investigated a 300MW coal-fire CFB boiler of the Zhongli power plant in Anhui Province, China. The boiler is a subcritical reheat type of natural circulation. The boiler is fueled with a mixture of coal slime and coal. The mixed burning of coal slime has brought considerable economic benefits to the Zhongli power plant. The general layout of the mix-burning coal slime CFB boiler unit is shown in Fig. 3.

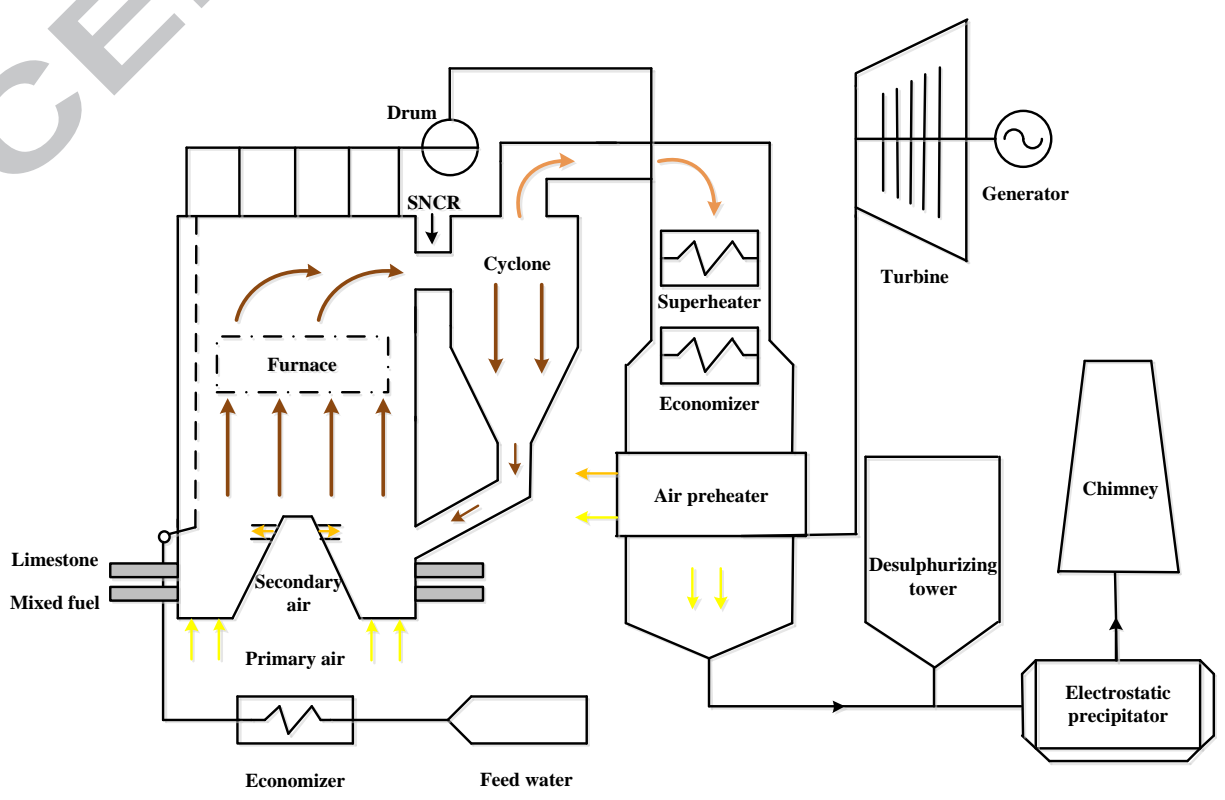

Fig. 3. General layout of the investigated CFB boiler unit. 
The mixed fuel pump system was designed by the German PUTZMEISTER company, and it consists of the fuel barn, the barn bottom sliding frame, flushing water pressurized pump and 4 slime pumping pipelines. In actual operation, the automatic combustion control of the unit is difficult due to the energy fluctuation caused by the mixed fuel pumping. Hence it is basically operated by manual control. The coal quality analysis of furnace fuel is shown in Table 1.

Tab.1 The coal quality analysis of furnace fuel

\begin{tabular}{ccc}
\hline Item & Coal & Coal slime \\
\hline Carbon (as received base) $(\%)$ & 41.46 & 26.13 \\
\hline Hydrogen (as received base) $(\%)$ & 2.40 & 1.70 \\
\hline Oxygen (as received base)(\%) & 5.98 & 4.47 \\
\hline Nitrogen (as received basis) (\%) & 0.83 & 0.62 \\
\hline Sulphur (as received basis) (\%) & 0.47 & 0.38 \\
\hline Ash content (as received basis) (\%) & 41.46 & 35.50 \\
\hline Moisture (as received basis) $(\%)$ & 7.40 & 31.20 \\
\hline Volatile matter (dry ash-free basis) $(\%)$ & 27.48 & 33.60 \\
\hline Net calorific value (MJ/kg) & 16.03 & 9.10 \\
\hline
\end{tabular}

\subsection{Preparation for modeling}

The preparation for modeling mainly focuses on the following three aspects: sample data, model output and model input.

\section{1) Sample data}

The sample data was selected from the actual operation data in the DCS of 300MW CFB boiler unit in Zhongli power plant, and these data were acquired with the time resolution of 20 seconds and approximately 5,029 data points in total were obtained. The historical data covered the usual common operation states between September and December in 2015. In the process of the CFB power plant, load changes quickly to make the whole power grid balance. However, when the process is not steady, system parameters are unstable, so the predictive model cannot provide off-line economic optimization with accurate stable operation cost. The steady-state detecting is divided into two parts: The primary selection was based on ASME PTC6 [20] and sliding window technology, and then the K-means outliers elimination algorithm was applied to further clean the data. The detailed process was as follows: the number of clusters was set to 3, and then the distances and the average distances between the every data point and the corresponding cluster center were separately calculated. If the distance between some point and the cluster center was three times larger than the average distance, then the point was eliminated [21]. After these, 3,022 groups of representative operation data were selected. Among them, 2,168 groups of data were used for training the model. The remaining 854 groups were applied to test the performance of the model. 


\section{2) Model output}

The operating cost of the unit mainly includes three parts: the fuel cost, the cost of desulphurization and denitrification, and the cost of power consumption. The composition schematic diagram of operating cost as shown in Figure 4.

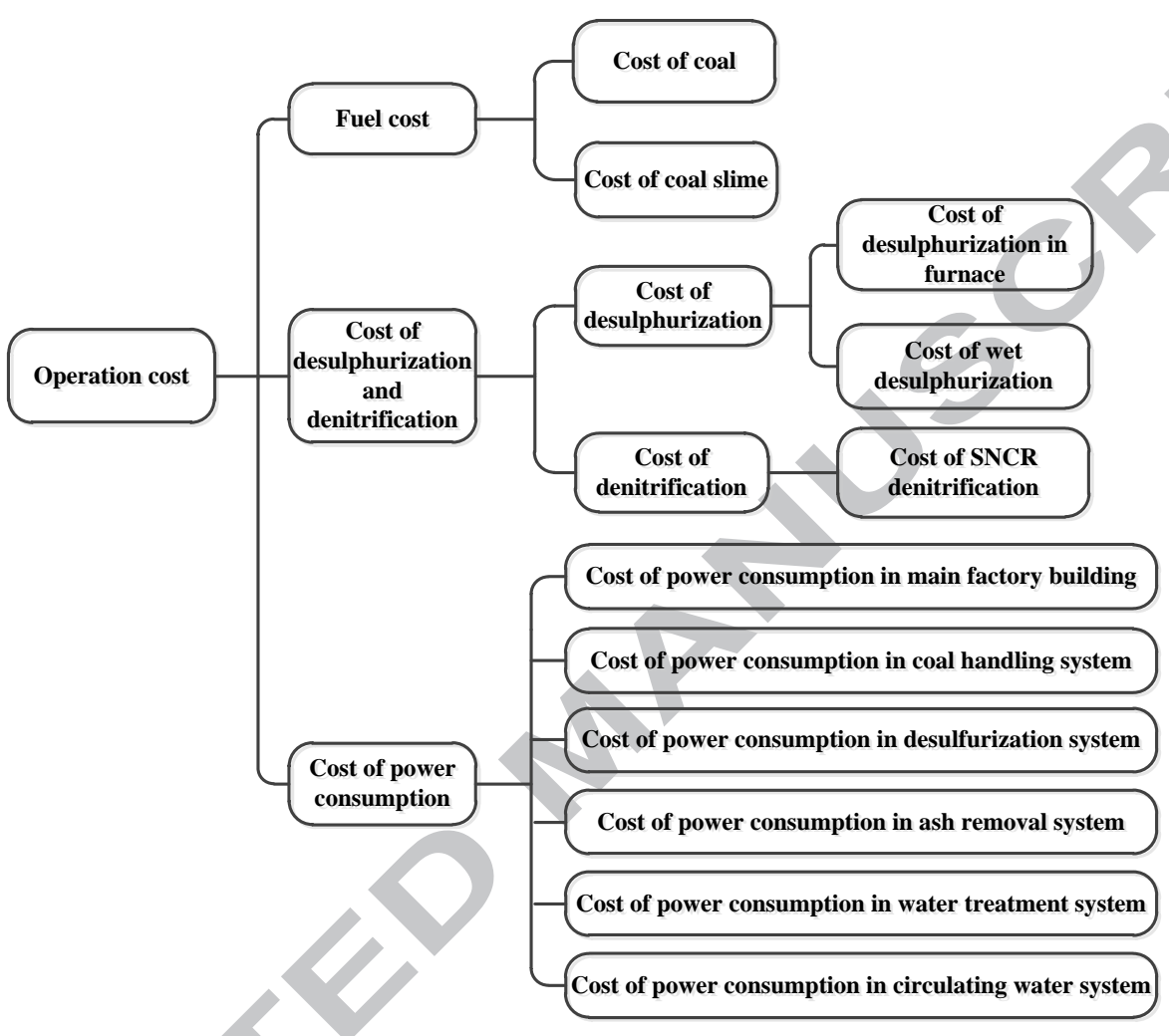

Fig. 4 .The composition schematic diagram of operation cost

$$
f=\frac{1}{3600}\left(C_{1} \cdot P_{1}+C_{2} \cdot P_{2}+C_{3} \cdot P_{3}+C_{4} \cdot P_{4}+1000 \cdot W \cdot \eta_{w} \cdot P_{5}\right)
$$

Where $f(\$ / \mathrm{s})$ is the operation cost of whole unit; $\boldsymbol{C}_{\boldsymbol{I}}(\mathrm{t} / \mathrm{h})$ is the coal consumption, $\boldsymbol{P}_{\boldsymbol{I}}(\$ / \mathrm{t})$ is the price of standard coal; $\boldsymbol{C}_{2}(\mathrm{t} / \mathrm{h})$ is coal slime consumption, $\boldsymbol{P}_{2}(\$ / \mathrm{t})$ is the price of coal slime; $\boldsymbol{C}_{3}(\mathrm{t} / \mathrm{h})$ is limestone consumption, $\boldsymbol{P}_{\mathbf{3}}(\$ / \mathrm{t})$ is the price of limestone; $\boldsymbol{C}_{\mathbf{4}}(\mathrm{t} / \mathrm{h})$ is the ammonia consumption, $\boldsymbol{P}_{\mathbf{4}}(\$ / \mathrm{t})$ is the price of ammonia; $\boldsymbol{W}(\mathrm{MW})$ is the power generation capacity of power plant, $\boldsymbol{\eta}_{\boldsymbol{w}}(\%)$ is station service power consumption rate, the product of the two represents the electric energy consumed by the equipment in the power generation process, which including the electrostatic precipitator, desulfurization tower and all kinds of fan etc., $\boldsymbol{P}_{5}(\$ /(\mathrm{kW} \cdot \mathrm{h}))$ is the electricity price. According to the formula (25), the operation cost of whole unit under the selected steady states can be calculated.

\section{3) Model input}

According to the mechanism and the correlation analysis, 32 variables were chosen as alternative inputs of the model preliminarily: the load of the boiler $\left(x_{1}\right)$; the temperature and flow rate of feedwater 
$\left(x_{2}, x_{3}\right)$; the steam drum level $\left(x_{4}\right)$; the temperature, pressure and flow rate of main steam $\left(x_{5}-x_{7}\right)$; the flow rate of desuperheating water $\left(x_{8}\right)$; the temperature, pressure and flow rate of reheat steam $\left(x_{9}-x_{11}\right)$; the temperature, pressure and flow rate of flue gas $\left(x_{12}-x_{14}\right)$; the oxygen content of flue gas $\left(x_{15}\right)$; the current of primary air fan $\left(x_{16}\right)$; the current of secondary air fan $\left(x_{17}\right)$; the current of fluidizing fan $\left(x_{18}\right)$; the current of induced draft fan $\left(x_{19}\right)$; the furnace pressure $\left(x_{20}\right)$; the speed of slag cooler $\left(x_{21}\right)$; the slag temperature $\left(x_{22}\right)$; the plant power consumption $\left(x_{23}\right)$; the bed temperature of the left side and right side $\left(x_{24}, x_{25}\right)$; the bed pressure of the left side and right side $\left(x_{26}, x_{27}\right)$; the total coal quantity from the coal feeder $\left(x_{28}\right)$; the coal slime quantity from pumping system $\left(x_{29}\right)$; the injection amount of denitrification agent $\left(x_{30}\right)$; the revolution of limestone frequency converter $\left(x_{31}\right)$; the current of electrostatic precipitator $\left(x_{32}\right)$. Finally, according to PMI method, 18 variables were screened from 32 input variables as the best model input variable set, and the screening process is shown in Figure 5. The AIC value continued to decline and reached the minimum value when 18 variables were screened out, and the minimum AIC value is -9692.0. Each extracted variable with the maximum information entropy in each selection process made up the best input variables set, and the final input variables set is $\left[x_{1}, x_{3}, x_{5}\right.$, $\left.x_{6}, x_{7}, x_{10}, x_{12}, x_{15}, x_{16}, x_{17}, x_{23}, x_{24}, x_{26}, x_{28}, x_{29}, x_{30}, x_{31}, x_{32}\right]$. Reducing the number of input variables can reduce the complexity of the model and avoid fitting, also can cause information reduction, but the best AIC value can guarantee the trade-off between information gain and the modeling complexity [22].

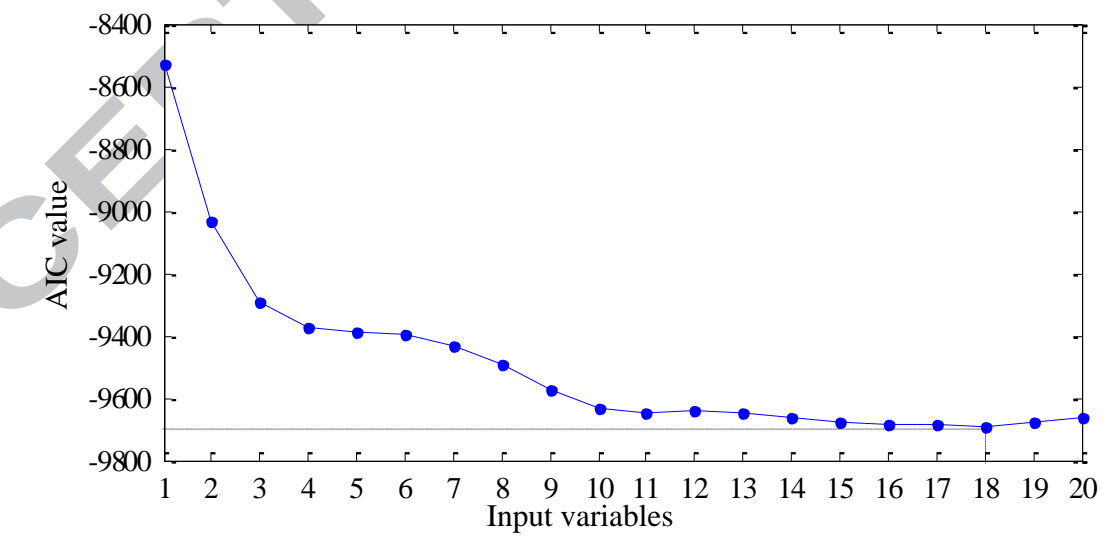

Fig.5 PMI screening process

\subsection{LSSVM prediction model}

To establish the LSSVM model, Gaussian RBF was employed as the kernel function. The values of kernel parameter $\sigma$ and penalty coefficient $\gamma$ were determined via 10 -fold cross-validation grid search method [23]. In the 10-fold cross-validation, the data set was divided into 10 groups, in which one group was used as test data in turn, and the other 9 groups were used as training data correspondingly. 
Furthermore, the average error of 10 tests served as the evaluation index of model parameters. The model parameters $\sigma$ and $\gamma$ were searched respectively in the range of $\left[2^{-2}, 2^{6}\right]$ and $\left[2^{-1}, 2^{15}\right]$, and then the best pair of $(\sigma, \gamma)$ with the minimum error was adopted as optimal model parameters [23]. After the cross validation, it can be drawn that the minimum error of the cross validation is 0.0242 under the condition that $\sigma=92.09, \quad \gamma=2068.31$.

Fig. 6 illustrates the parity plots of training data and testing data. It is easy to see that the data are diagonal in distribution along the perfect correlation line, which means the established model can achieve an excellent prediction of operation cost.

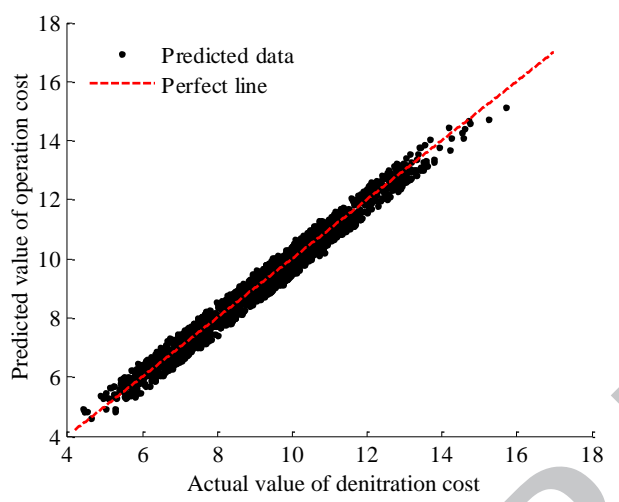

(a) Training samples

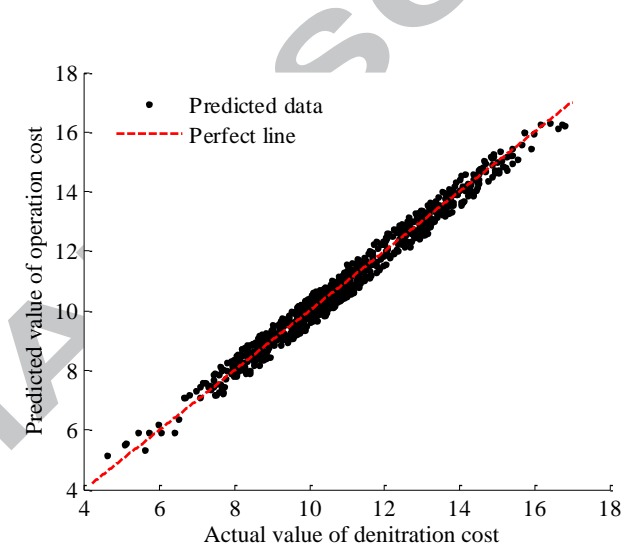

(b) Test samples

Fig. 6 Parity plot of the actual data vs. predicted data

In addition, for comparison purpose, the support vector machine (SVM) and Elman neural network models of operation cost are also established. In order to make the comparison of the three models, the performances are evaluated in terms of root mean square error (RMSE) and mean relative error (MRE) criteria, which are defined as Eqs. (26) and (27). The RMSE and MRE values of three models are shown in Tab.2, the detailed relative errors between the actual and predicted values on testing data using the three models are shown in Fig.7.

$$
\begin{gathered}
R S M E=\sqrt{\sum_{i=1}^{n}\left(f_{i}-\hat{f}_{i}\right)^{2} / n} \\
M R E=\frac{1}{n} \sum_{i=1}^{n}\left|\frac{f_{i}-\hat{f}_{i}}{\hat{f}_{i}}\right|
\end{gathered}
$$

where $\boldsymbol{n}$ is the number of samples, $f_{i}$ is the actual measured operation cost and $\hat{f}_{i}$ is the corresponding predicted value. 
Tab.2 Comparison for RMSE and MRE values of three models

\begin{tabular}{cccc}
\hline Model & SVM & ELMAN & LSSVM \\
\hline RMSE & 0.6921 & 0.4237 & 0.2887 \\
\hline MRE & 0.0479 & 0.0289 & 0.0237 \\
\hline
\end{tabular}

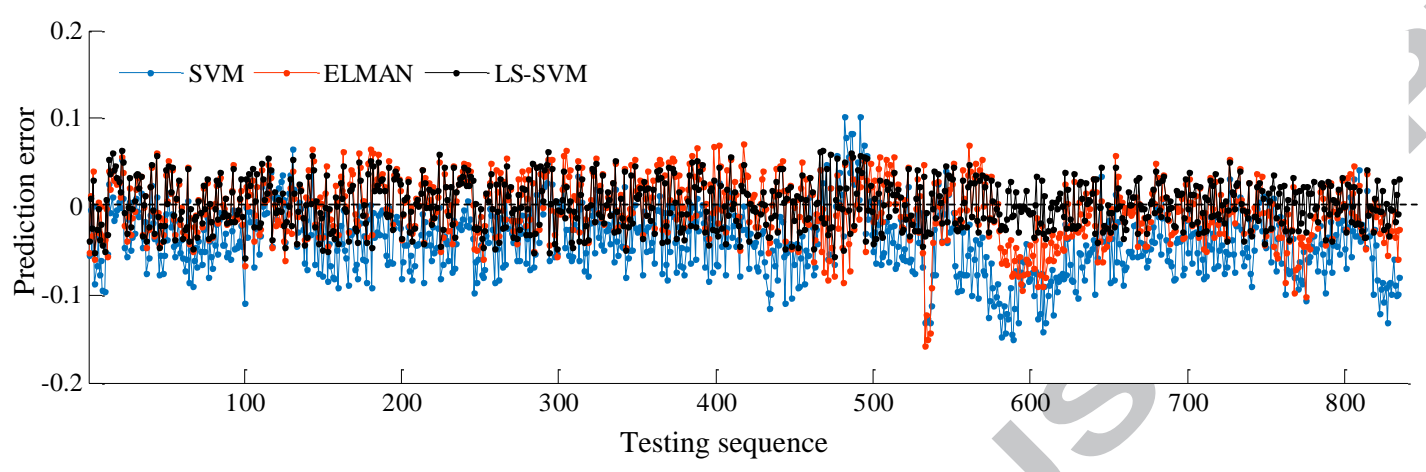

Fig.7 Errors comparison for three models

Compared with the methods of SVM and Elman neural network, the RMSE and MRE value of the LSSVM model are respectively 0.2887 and 0.0237 which shows that the LSSVM model exhibits good approximation accuracy and the estimation errors vary within a small range. Besides, in terms of training time and running speed, the LSSVM and Elman neural network models have superiority over SVM, and they separately spend about 120 s and 146 s to search the optimal parameters pair and train the model, which is almost one-tenth of the time spent by SVM. In addition, Elman neural network is easy to fall into local minimum and has the defects like large randomness and overfitting [24]. In comparison, LSSVM has advantages in accuracy, rapidity and stability.

The optimization system is based on data-driven methods, the operation cost prediction and optimization is achieved by training and mining of historical data. If the parameters of coal slime are changed, the database of control parameters in the optimization system should be updated after the unit parameters are adjusted to accommodate fuel changes. The sliding window technology was adopted as regular update strategy to avoid the model failure caused by the change of unit performance.

The share of coal slime which is reflected in the amount of coal and coal slime in the historical database. The operation states with $0-55 \%$ shares of coal slime can be covered in common actual operation of mix-burning CFB boiler unit. The change in the shares of coal slime between $0-55 \%$ does not affect the function of the optimized system. At present, some scholars have carried out tests to prove the maximum share of coal slime in fuel mixture can reach $70 \%$ [25]. However, during the tests, the operating conditions of the unit are ideal, and the interference factors are few, which often cannot 
represent the complexity in the actual continuous operation. Thus the shares of coal slime between 0 $55 \%$ is common.

\subsection{Off-line optimal expert knowledge database}

Based on the established operation cost prediction model, the off-line expert knowledge base was established by using GA to optimize 1600 groups of working conditions covers the common operation states, which were under different loads (160-300MW) within the security threshold. In order to reduce the influence of significant changes caused by population evolutionary on the dynamic characteristics of the unit, the optimal range of control variables needed to be limited. Each 200 groups of historical stable operation states with approximate specified load were integrated as one control variable data set which was defined as $D$. When the control variables were optimized under the specified load, the upper and lower thresholds of $D$ were taken as the optimal search range, thus the safe and stable operation of the unit can be guaranteed. The population number $M$, the evolutionary termination time $T$, the crossover probability $P_{c}$, the mutation probability $P_{m}$ are $100,300,0.4,0.1$ respectively. After the GA optimization, the quantitative value of the optimal operation states in the EKD can be obtained in

Tab.3.

Tab.3 Off-line expert knowledge base

\begin{tabular}{|c|c|c|c|c|c|c|}
\hline \multirow{2}{*}{\multicolumn{2}{|c|}{$\begin{array}{c}\text { Operating point } \\
\text { Value type }\end{array}$}} & \multicolumn{2}{|l|}{1} & \multirow{2}{*}{$\frac{}{\ldots}$} & \multicolumn{2}{|c|}{1600} \\
\hline & & Quantitative value & Fuzzy vector & & Quantitative value & Fuzzy vector \\
\hline Load/MW & $Q$ & 163.11 & NB & $\cdots$ & 297.32 & PB \\
\hline Flow rate of feedwater/(t/h) & $X_{-Q 1}$ & 535.29 & NB & $\cdots$ & 537.57 & NS \\
\hline Main steam temperature $/{ }^{\circ} \mathrm{C}$ & $X_{-Q 2}$ & 9.96 & NB & $\cdots$ & 16.26 & PB \\
\hline Main steam pressure/MPa & $X_{-Q 3}$ & 513.32 & NB & $\cdots$ & 897.18 & $\mathrm{~PB}$ \\
\hline Flow rate of main steam/(t/h) & $X_{-Q 4}$ & 555.70 & NB & $\cdots$ & 901.62 & PB \\
\hline Reheat steam pressure/MPa & $X_{-Q 5}$ & 126.79 & NS & $\cdots$ & 131.89 & PB \\
\hline Flue gas temperature $/{ }^{\circ} \mathrm{C}$ & $X_{-Q 6}$ & 6.07 & PB & $\cdots$ & 4.05 & NB \\
\hline Oxygen content of flue gas $/ \%$ & $X_{-Q 7}$ & 151.80 & NB & $\cdots$ & 146.88 & $\mathrm{Z}$ \\
\hline Current of primary air fan/A & $X_{-Q 8}$ & 60.11 & NB & $\cdots$ & 127.81 & PB \\
\hline Current of secondary air fan/A & $X_{-Q 9}$ & 1.64 & NB & $\cdots$ & 2.92 & PB \\
\hline Plant power consumption/(kW·h) & $X_{-Q 10}$ & 2.75 & NB & $\cdots$ & 4.92 & PB \\
\hline Bed temperature of the left side $/{ }^{\circ} \mathrm{C}$ & $X_{-Q 11}$ & 910.54 & PS & $\cdots$ & 901.00 & NS \\
\hline Bed pressure of the left side/MPa & $X_{-Q 12}$ & 6.05 & NB & $\cdots$ & 7.70 & PB \\
\hline Total coal amount from the coal feeder(t/h) & $X_{-Q 13}$ & 51.14 & NB & $\cdots$ & 117.89 & PB \\
\hline Total coal slime amount from pumping system(t/h) & $X_{-Q 14}$ & 31.72 & NB & $\cdots$ & 56.50 & PB \\
\hline Denitrification agent injection amount(m3/h) & $X_{-Q 15}$ & 224.44 & PS & $\cdots$ & 167.50 & NS \\
\hline Limestone frequency converter revolution(r/min) & $X_{-Q 16}$ & 1.34 & $\mathrm{~PB}$ & $\cdots$ & 1.23 & NB \\
\hline Current of electrostatic precipitator/A & $X_{-Q 17}$ & 101.27 & NB & $\cdots$ & 113.50 & NS \\
\hline Operation cost/(\$/s) & $f$ & 1.02 & / & $\ldots$ & 1.62 & / \\
\hline
\end{tabular}




\subsection{IFARM operation cost optimization and model comparisons}

According to the steps of IFARM algorithm, the quantitative values in the EKD should be fuzzified firstly. The normalization interval and the number of fuzzy sets are $[-3.5,3.5]$ and 5 , and the corresponding linguistic variables are NB (negative big), NS (negative small), Z (zero), PS (positive small), and PB (positive big) in turn. K-means was used to do clustering analysis of the variables in the knowledge database and obtain the cluster centers as center points $\left(\mathrm{c}_{1}-\mathrm{c}_{5}\right)$ of each fuzzy set. The widely used trigonometric membership function is adopted because the sharper the membership function is, the higher the resolution is. In the area where the input is small, a higher resolution curve which is as sharp as trigonometric membership function should be a better choice. Besides, the shape of membership function is generally less important than the number of curves and their placement. The adopted trigonometric membership function is shown in Fig.5.

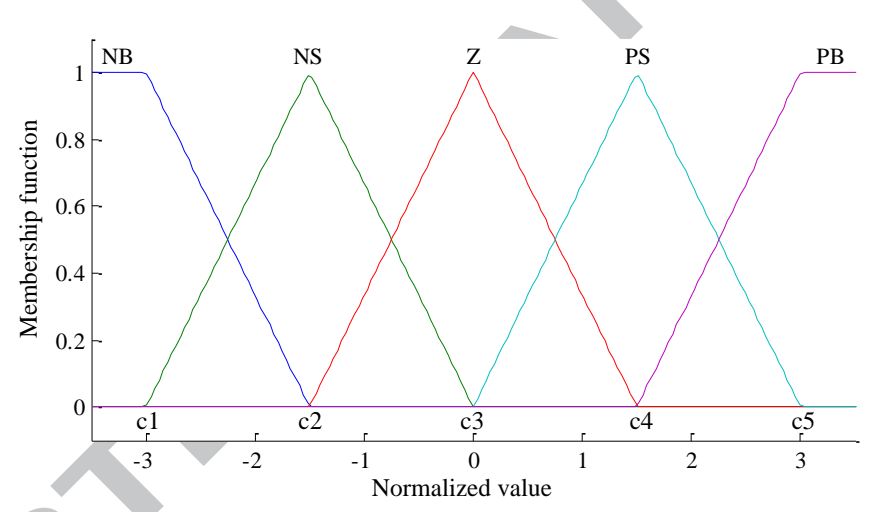

Fig.8 Membership function of fuzzification.

Fuzzy vectors and memberships can be obtained by fuzzy level discretization and membership degrees calculation, and the initial rule base was obtained. Then, after arrangement and counting, the minimum support $\boldsymbol{s}_{\min }$ and minimum confidence $\boldsymbol{c}_{\min }$ were used as the first screening criteria of association rules, which were respectively assigned the values 0.45 and 0.75 . Finally, the economic utilities were calculated as the final screening criteria, the obtained fuzzy association rule base, as shown in Tab. 4, provided the final control rules for the reasoning and on-line optimization.

Tab.4 Fuzzy association rules

\begin{tabular}{|c|c|c|c|c|c|c|c|c|c|c|c|c|c|c|c|c|c|}
\hline$Q$ & $X_{-Q I}$ & $X_{Q^{Q 2}}$ & $X_{-Q}$ & $X_{-Q}$ & $X_{-Q}$ & $X_{\cdot}$ & $X_{-Q}$ & $X_{Q_{Q}}$ & $X_{\cdot Q}$ & $X_{Q_{Q I}}$ & $X_{-Q 1}$ & $X_{-Q 1}$ & $X_{-Q I}$ & $X_{-Q I}$ & $X_{-Q 1}$ & $X_{Q_{Q I}}$ & $X_{Q_{Q I}}$ \\
\hline NB & NB & NB & NB & NB & NB & PS & NS & NB & NB & NB & PS & $\mathrm{Z}$ & NB & NB & PS & Z & NB \\
\hline NS & NS & PS & NS & Z & Z & NS & NB & NS & Z & NS & $\mathrm{Z}$ & $\mathrm{Z}$ & $\mathrm{Z}$ & Z & Z & NB & NS \\
\hline $\mathrm{Z}$ & NS & PB & Z & Z & Z & NB & NB & NS & $\mathrm{Z}$ & NS & NS & NB & NS & Z & $\mathrm{NB}$ & NS & NS \\
\hline PS & NB & PB & PS & Z & NS & $\mathrm{Z}$ & NB & PS & PS & NS & NB & Z & NB & Z & Z & NB & Z \\
\hline PB & NS & PB & PB & PB & PB & PS & Z & PS & PB & PS & $\mathrm{Z}$ & $\mathrm{PB}$ & $\mathrm{Z}$ & PB & NB & NS & $\mathrm{Z}$ \\
\hline
\end{tabular}

When an input fuzzy value is received, the fuzzy controller completed the fuzzy inference by 
fuzzy association rules, and obtained the fuzzy control quantity. To verify the performance of the IFARM algorithm, IFARM optimization of the operation states shown in Tab. 5 which formed a comparison with GA optimization in off-line expert knowledge base. It can be seen from Tab.3 and Tab. 5 that the optimization effect of IFARM is generally better than GA.

Tab.5 Expert knowledge base after IFARM optimization

\begin{tabular}{|c|c|c|c|c|}
\hline Operating point & & 1 & $\ldots$ & 1600 \\
\hline Value type & & Quantitative value & $\ldots$ & Quantitative value \\
\hline Load/MW & $Q$ & 163.11 & $\cdots$ & 297.32 \\
\hline Flow rate of feedwater/(t/h) & $X_{-Q I}$ & 533.15 & $\cdots$ & 535.74 \\
\hline Main steam temperature $/{ }^{\circ} \mathrm{C}$ & $X_{-Q 2}$ & 10.39 & $\cdots$ & 16.36 \\
\hline Main steam pressure/MPa & $X_{-Q 3}$ & 498.56 & & 902.46 \\
\hline Flow rate of main steam/(t/h) & $X_{-Q 4}$ & 509.62 & & 897.71 \\
\hline Reheat steam pressure/MPa & $X_{-Q 5}$ & 122.85 & $\cdots$ & 134.59 \\
\hline Flue gas temperature $/{ }^{\circ} \mathrm{C}$ & $X_{-Q 6}$ & 3.95 & $\cdots$ & 3.95 \\
\hline Oxygen content of flue gas $/ \%$ & $X_{-Q 7}$ & 149.42 & $\cdots$ & 151.69 \\
\hline Current of primary air fan/A & $X_{-Q 8}$ & 60.19 & $\cdots$ & 103.45 \\
\hline Current of secondary air fan/A & $X_{-Q 9}$ & 1.677 & $\cdots$ & 2.97 \\
\hline Plant power consumption/(kW·h) & $X_{-Q 10}$ & 2.43 & $\cdots$ & 4.43 \\
\hline Bed temperature of the left side $/{ }^{\circ} \mathrm{C}$ & $X_{-Q 11}$ & 913.70 & $\cdots$ & 902.52 \\
\hline Bed pressure of the left side/MPa & $X_{-Q 12}$ & 7.05 & $\cdots$ & 7.74 \\
\hline Total coal amount from the coal feeder( $\mathrm{t} / \mathrm{h})$ & $X_{-Q 13}$ & 46.68 & $\cdots$ & 87.19 \\
\hline Total coal slime amount from pumping system $(\mathrm{t} / \mathrm{h})$ & $X_{-Q 14}$ & 32.51 & $\cdots$ & 64.02 \\
\hline Limestone frequency converter revolution(r/min) & $X_{-Q 15}$ & 234.91 & $\cdots$ & 84.64 \\
\hline Denitrification agent injection amount $(\mathrm{m} 3 / \mathrm{h})$ & $X_{-Q 16}$ & 1.24 & $\cdots$ & 1.23 \\
\hline Current of electrostatic precipitator/A & $X_{-Q 17}$ & 96.92 & $\cdots$ & 109.11 \\
\hline Operation cost/(\$/s) & $f$ & 0.89 & & 1.47 \\
\hline
\end{tabular}

The GA model and the FARM optimization model which used Interest as the criterion of fuzzy association rule selection in Ref. [12] and [17] were also established to make a comparison. 830 groups of working conditions covered the common operation loads (160-300MW) were taken as test data and the load data in the test data were inputted into the GA, FARM, and IFARM three optimization algorithm. Then, both the three obtained optimal operation states were substituted into PMI-LSSVM operation cost prediction model in Section 3.3. Fig. 6 shows the operation cost comparison results between the three optimizations and the original data under the given load. 


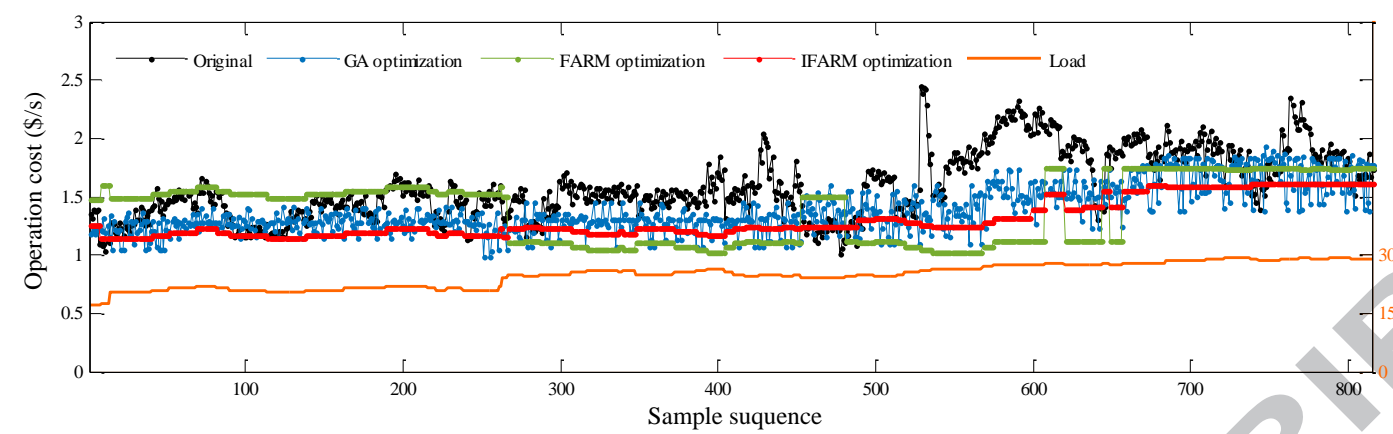

Fig.9 Comparison between the three optimization effects and the original data

Tab. 6 Comparison of three optimization effectiveness

\begin{tabular}{cc}
\hline & Average operation $\operatorname{cost} /(\$ / \mathrm{s})$ \\
\hline Original data & 1.57 \\
\hline GA optimization & 1.39 \\
\hline FARM optimization & 1.40 \\
\hline IFARM optimization & 1.31 \\
\hline
\end{tabular}

It can be seen from Fig. 6 and Tab. 6 that the all three algorithms can reduce operation cost in terms of the optimization effect, but the optimization effect of IFARM is generally better than GA and FARM. The average operation cost of IFARM optimization is $1.31 \$ / \mathrm{s}$, which is less than FARM and GA. In contrast with the cost reduction by FARM in Ref. [12] which is 5.75\%, the adoption of IFARM can save $16.7 \%$ of the original operation cost for the whole unit which shows a good performance of IFARM. And the $0.1 \$ / \mathrm{s}$ gap between FARM and GA also proves the conclusion of Ref. [12] that the optimization effect of FARM was not as good as the GA achieved. However, the optimization effect of IFARM is improved in a targeted manner by the improvement and adoption of the Utility cost instead to Interest as the fuzzy association rule selection criterion.

As mentioned in Ref. [12], the results of GA method vary frequently in a wide range which will increase the valves wear and aging, while the values corresponding to the FARM and IFARM method vary very smoothly and avoid the frequent switching. Besides, compared with GA, the IFARM have the same advantages about optimize speed and stability with FARM. In terms of the optimize speed and the complexity of the algorithm, the IFARM algorithm and FARM algorithm can be hundreds of times as fast as that of GA optimization. Furthermore, for GA it is difficult to achieve fast online optimization because of the high CPU occupancy rate, which potentially reduces the reliability of the system.

Fig.7 shows the values of some typical control parameters corresponding to the original and the GA method, the FARM method and the IFARM method under the same load instructions as Fig.6. In 
order to reduce operation costs, all three methods reduce the operation cast comprehensively considering the costs of fuel, desulfurization, denitrification, and power consumption, which are directly related to the typical control parameters in following figures. As the amount of coal slime in the furnace increases, the boiler thermal efficiency will decrease. For example, as researchers calculated in Ref. [26], the amount of coal slime was set to be $52 \mathrm{~m}^{3} / \mathrm{h}$ (40\% of fuel mixture), then the boiler thermal efficiency dropped by about $1.5 \%$ compared with the case without coal slime at the load of 260 MW. Besides, mix-burning coal slime makes the bed temperature and the main steam temperature reduced, the primary air volume increased, and the $\mathrm{SO}_{2}$ and $\mathrm{NO}_{\mathrm{x}}$ increased to different degrees. Although the mix-burning coal slime can increase the economic efficiency of the unit, in order to operate safely and stably, the amount of coal slime cannot be increased blindly in the actual operation. It also needs to be weighed against factors such as boiler heat storage and emissions of $\mathrm{SO}_{2}$ and $\mathrm{NO}_{\mathrm{x}}$.
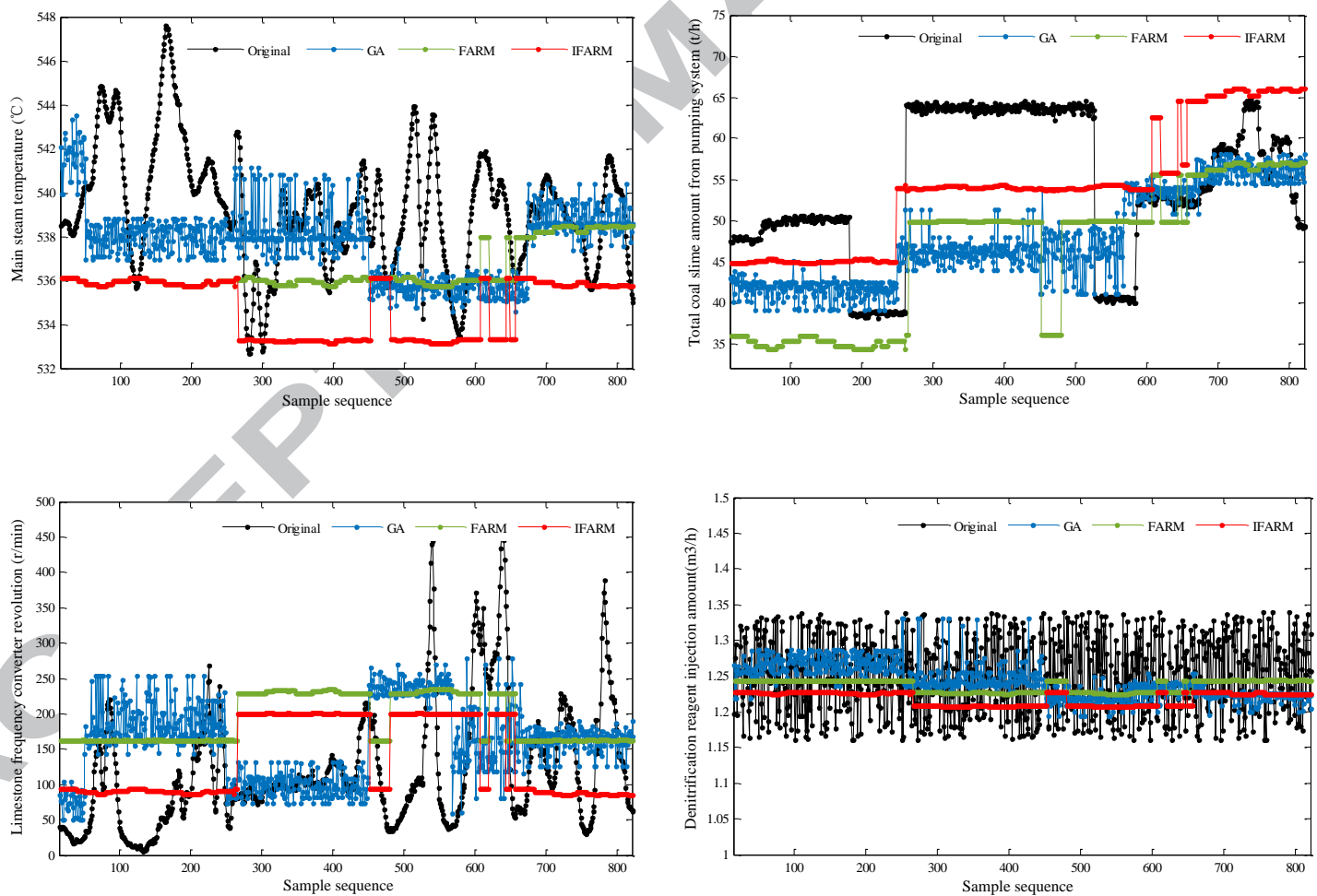

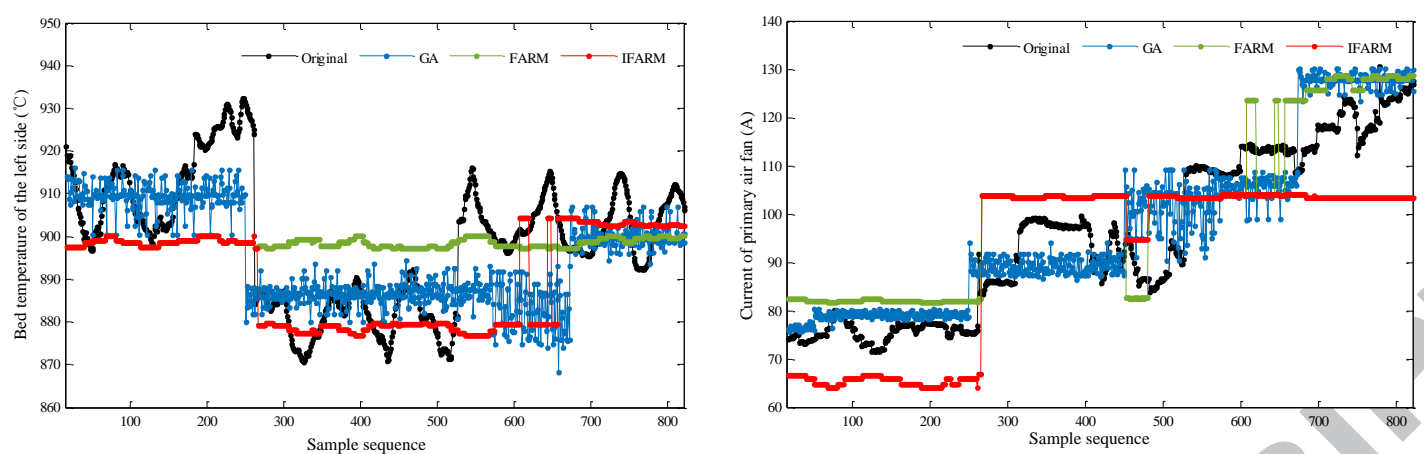

Fig.10 Typical control parameters of three optimization and the original

\section{Conclusions}

Taking an actual operating 300MW mix-burning coal slime circulating fluidized bed boiler unit as example, this study proposed a data-base operation cost optimization system providing optimal control target values for different control variables. For a CFB boiler unit with about 5000 utilization hours per year of power generation, the optimization system can save about 4.7 million $\$ /$ year, which is remarkable under the situation of coal supply shortage for power generation. By comparing with different models, the optimization effect of the proposed model has advantages. Thus the proposed operation cost optimization system is a valid tool for the given type and size of CFB boiler unit. Moreover, the data mining method can be expanded and reference for other optimization functions in other engineering fields. Some specific comparison conclusions were obtained as follows:

The accuracy of the whole optimization system for operation costs mainly includes two parts: the prediction accuracy of the operation cost model and the optimization accuracy of the control variable target value. The PMI-LSSVM model of operation cost was established, and prediction accuracy indicators mean relative error and root mean square error of the model were 0.0237 and 0.2887 respectively. LSSVM method had advantages in accuracy, rapidity and stability through the comparison with SVM and Elman methods. The average operation cost after using the proposed optimization system is $1.31 \$ / \mathrm{s}$, which can save $16.7 \%$ of the original operation cost, and $0.08 \$ / \mathrm{s}, 0.09$ \$s less than GA and FARM optimization respectively. The IFARM can reconstruct and update in 0.696 seconds which can be hundreds of times as fast as that of GA. The EKD was constructed under safe threshold of historical data, which guarantees global optimum and operation safety. The IFARM method introduced utility cost into association rule measurement standard, and fuzzy association rules with both matching degree and economy were targetedly and quickly screened. 


\section{Acknowledgements}

This project is supported by the National Key Research and Development Program (2016YFB0600205) and the Fundamental Research Funds for the Central Universities (2016MS28, 2017XS072, 2018ZD05). The authors would like to thank Zhongli power plant and Excellent

Chinese and Foreign Youth Exchange Program of China Association for Science and Technology for the support.

\section{Nomenclature}

$b$

$C$

$C_{1^{-}} C_{4}$

Cs

$c$

$\mathrm{c}_{1}-\mathrm{c}_{5}$

$c_{\text {min }}$

D

$d$

E

$F_{e}$

$f$

$f_{e}$

$f_{i}$

$\hat{f}_{i}$

$h$

$H(X)$

$H(X, Y)$

$H(X / Y)$

I

I

$I(X, Y)$

$I(Z, Y)$

$i$

j

$K\left(x_{\mathrm{i}}, x_{\mathrm{j}}\right)$

$M$

m

$m_{t}$

$m_{Y}(X)$

$m_{z}(X)$

$n$

$n_{r}$

$n_{v}$

The bias

The set of input variables

The consumptions of the component of operating costs

The candidate variable

The confidence

The center points of the fuzzy sets

The minimum confidence

The control variable data set

The dimension of $X$

The utility cost

The economic index of the fuzzy item sets

The vector of the operation cost

The normalized operation cost of unit in the EKD

The operation cost of unit

the predicted operation cost

The kernel bandwidth

The information entropy of $X$

The two-dimensional joint entropy of $(X, Y)$

The conditional entropy of $X$ when $Y$ is known

The Interest index

A $n \times n$ element matrix

The partial mutual information of $X$ and $Y$

The partial mutual information between $Z$ and $Y$

The serial number of control variables $X_{-Q}$ under the same operation state

The serial number of different transactions in the data set

The kernel function

The population number

The serial number of operation states in the EKD;

The total number of transactions in the data set

The information of $X$ contained in $Y$

The information of $X$ contained in $Z$

The number of observation samples

The number of the rules

The number of selected variables 


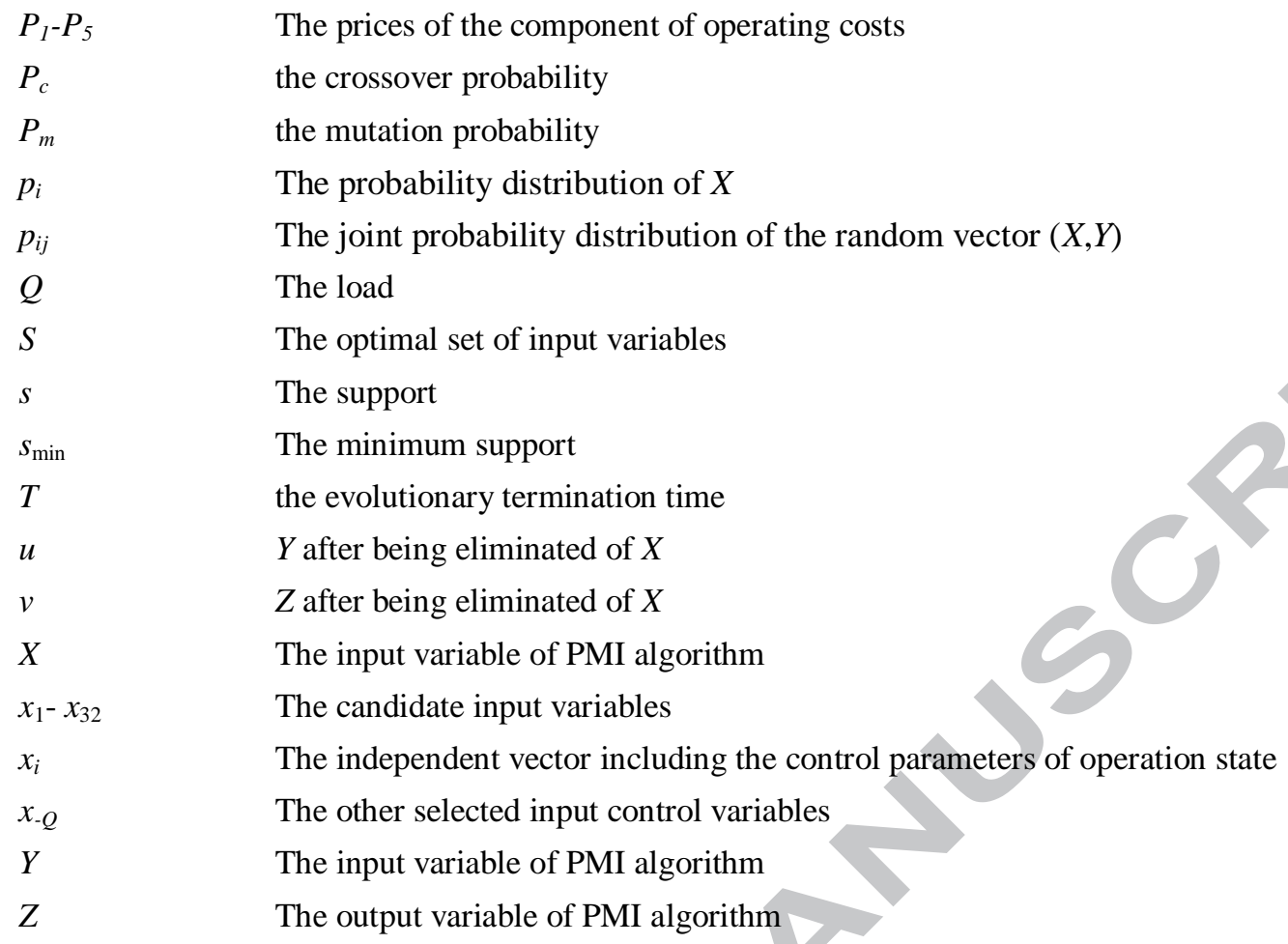

\section{Greeks}

$\alpha$

$\sigma$

$w$

$\xi$

$\gamma$

$\Sigma$

$\Omega_{\mathrm{ij}}$

$\varphi(\cdot)$

$\mu(Q)$

Abbreviations

AIC

CFB

DCS

EKD

GA

IFARM

LSSVM

MRE

PMI

RBF

RMSE

SVM
The Lagrange multiplier vector

The kernel parameter.

The weight vector

The error variable vector

The penalty coefficient

The covariance matrix

The kernel function

A nonlinear mapping

The membership function of $Q$

Akaike information criterion

Circulating fluidized bed

Distributed control system

Expert knowledge database

Genetic algorithm

Improved fuzzy association rules mining

Least squares support vector machine

Mean relative error

Partial mutual information

Radial basis function

Root mean square error

Support vector machine 


\section{References}

[1] China Huaneng Group Co., Ltd, China Datang Group Co., Ltd, China Huadian Group Co., Ltd, State Power Investment Co., Ltd. An urgent report on the current situation of coal supply for power generation, January, 2018; Site accessed http://finance.ifeng.com/a/20180126/15951212_0.shtml >.

[2] The U.S. Energy Information Administration (EIA). Coal Prices and Outlook; March 30, 2017; Site accessed < https://www.eia.gov/energyexplained/index.php?page=coal_prices >

[3] The Economic Times. Coal India raises thermal coal prices by 9\%; Jan 9, 2018; Site accessed < https://economictimes.indiatimes.com/industry/indl-goods/svs/metals-mining/coal-india-raises-th ermal-coal-prices-by-9/articleshow/62422391.cms >.

[4] Pengwei Li, Dongjie Yang, Xueqing Qiu, Weisheng Feng. Study on enhancing the slurry performance of coal-water slurry prepared with low-rank coal, Journal of Dispersion Science and Technology. 36 (2015) 1247-1256.

[5] You Lv, Feng Hong, Tingting Yang, Fang Fang, Jizhen Liu. A dynamic model for the bed temperature prediction of circulating fluidized bed boilers based on least squares support vector machine with real operational data, Energy. 124 (2017) 284-294.

[6] Artur Blaszczuka, Anna Zylka, Jacek Leszczynski. Simulation mass balance model behaviour in a large-scale circulating fluidized bed reactor. Particuology, 25(2016), 51-58.

[7] Artur Błaszczuk, Wojciech Nowak, Szymon Jagodzik. Effects of operating conditions on deNOx system efficiency in supercritical circulating fluidized bed boiler. Journal of Power Technologies, 93(1)(2013), 1-8.

[8] Tengfei Jiang, Debin Yin, Dewei Li, Yugeng Xi, Wu Zhou. Circulating fluidized bed coal-saving optimization control method, International Conference on Intelligent Computing for Sustainable Energy and Environment, Springer, Berlin, Heidelberg; pp.303-312, 2012.

[9] Mingming Gao, Bao Zhang, Feng Hong, Feng Chen. Design and application of the feed water control strategy for a $350 \mathrm{MW}$ circulating fluidized bed boiler, Applied Thermal Engineering. 125 (2017) 1-8.

[10] Aboozar Hadavand, Ali Akbar Jalali, Parviz Famouri. An innovative bed temperature-oriented modeling and robust control of a circulating fluidized bed combustor, Chemical Engineering Journal. 140 (2008) 497-508. 
[11] Zhongjie Wang, Ning Han, Jia Wang. The Study on the Fuzzy Control Algorithm for Main Steam Pressure Control of Circulated Fluidized Bed Boiler, Advanced Materials Research, 383(2012), 2092-2096. Trans Tech Publications.

[12] Tingting Yang, Chao Cui, Yali Shen, You Lv. A novel denitration cost optimization system for power unit boilers, Applied Thermal Engineering. 96 (2016) 400-410.

[13] Jaroslaw Krzywanski, Marta Wesolowska, Artur Blaszczuk, Anna Majchrzak, Maciej Komorowski, Wojciech Nowak. Fuzzy logic and bed-to-wall heat transfer in a large-scale CFBC. International Journal of Numerical Methods for Heat \& Fluid Flow, 28(1)(2018), $254-266$.

[14] J.Krzywanski, M. Wesołowska, A. Błaszczuk, A. Majchrzak, M. Komorowski, W. Nowak. The non-iterative estimation of bed-to-wall heat transfer coefficient in a CFBC by fuzzy logic methods. Procedia Engineering, 157(2016), 66-71.

[15] Artur Blaszczuk, Jaroslaw Krzywanski. A comparison of fuzzy logic and cluster renewal approaches for heat transfer modeling in a $1296 \mathrm{t} / \mathrm{h}$ CFB boiler with low level of flue gas recirculation. Archives of Thermodynamics, 38(1)(2017), 91-122.

[16] Ashish Mangalampalli, Vikram Pudi. Fuzzy association rule mining algorithm for fast and efficient performance on very large datasets, IEEE International Conference on Fuzzy Systems; pp.1163-1168, 2009.

[17] Jianqiang Li, Jizhen Liu, Luanying Zhang, Chenglin Niu. The Research and Application of Fuzzy Association Rule Mining in Power Plant Operation Optimization, Proc. CSEE. 26 (2006) 118-123 (in Chinese).

[18] Claude Elwood Shannon. A mathematical theory of communication, ACM SIGMOBILE Mobile Computing and Communications Review. 5 (2001) 3-55.

[19] Bernard W. Silverman. Density estimation for statistics and data analysis. London: Chapman \& Hall, 1986.

[20] ASME, 2004, Steam Turbines, Performance Test Codes, ASME PTC 6-2004.

[21] Anil K Jain. Data clustering: 50 years beyond k-means, Joint European Conference on Machine Learning and Knowledge Discovery in Databases; pp. 3-4, 2008. 
[22] Robert J. May, Holger R. Maier, Graeme C. Dandy, TMK Gayani Fernando. Non-linear variable selection for artificial neural networks using partial mutual information, Environmental Modelling \& Software. 23 (2008) 1312-1326.

[23] You Lv, Jizhen Liu, Tingting Yang, Deliang Zeng. A novel least squares support vector machine ensemble model for NOx emission prediction of a coal-fired boiler, Energy. 55 (2013) 319-329.

[24] Zhongji Qi, Mandan Liu, and Honggang Wang. Process modeling method based on an improved Elman Neural Network, IEEE World Congress on Intelligent Control and Automation (WCICA); pp. 8188-8192, 2008.

[25] Zhong Huang, Jianzhong Jiang, Zhengquan Xu, Lintao Cao, Xianbin Sun, Ping Xiao, Lijin Ma. Research on CFB Boiler Large Proportion Coal Slime Co-combustion Test, Proceedings of the CSEE. 33 (2013), 112-116 (in Chinese)

[26] Yanpen Liu, Jianmin Li, Yongsheng Yu, Bin Ma. Test study on mixedly burning coal slime in 300 MW CFB boiler, Thermal Power Generation. 39 (2010) 60-64 (in Chinese). 
Highlights:

- A $300 \mathrm{MW}$ system for mix-burning coal slime in a CFB unit is studied.

- A novel operation cost optimization system is proposed.

- Fast online instructs can be supplied to operators for better operation. 